\title{
Mendelian inheritance, genetic linkage, and genotypic disequilibrium at nine microsatellite loci of Cariniana legalis (Mart.) O. Kuntze
}

\author{
E.V. Tambarussi ${ }^{1}$, R. Vencovsky ${ }^{1}$, M.L.M. Freitas ${ }^{2}$ and A.M. Sebbenn ${ }^{3}$ \\ ${ }^{1}$ Departamento de Genética, Escola Superior de Agricultura "Luiz de Queiroz", \\ Universidade de São Paulo, Piracicaba, SP, Brasil \\ ${ }^{2}$ Instituto Florestal de São Paulo, São Paulo, SP, Brasil \\ ${ }^{3}$ Estação Experimental de Tupi, Instituto Florestal de São Paulo, Piracicaba, \\ SP, Brasil
}

Corresponding author: A.M. Sebbenn

E-mail: alexandresebbenn@yahoo.com.br

Genet. Mol. Res. 12 (4): 5442-5457 (2013)

Received February 28, 2013

Accepted July 17, 2013

Published November 11, 2013

DOI http://dx.doi.org/10.4238/2013.November.11.6

\begin{abstract}
Cariniana legalis is one of the largest tropical trees with a wide distribution in the Brazilian Atlantic rainforest. We investigated the Mendelian inheritance, genetic linkage, and genotypic disequilibrium at seven microsatellite loci specifically isolated for $C$. legalis, and at two previously developed heterologous microsatellite loci. Forty to 100 open-pollinated seeds were collected from 22 seed-trees in two populations. Using the Bonferroni correction, no remarkable deviations from the expected Mendelian segregation, linkage, or genotypic disequilibrium were detected in the nine loci studied. Only $3.7 \%$ of the tests were significant for investigations of the Mendelian proportions. On the other hand, only $2.8 \%$ of tests for linkage detection showed significance. In addition, among all pairwise tests used for investigating linkage disequilibrium, significance was found in $9.7 \%$ of the locus pairs. Our results show clear evidence that
\end{abstract}


the nine simple sequence repeat loci can be used without restriction in genetic diversity, mating system, and parentage analyses.

Key words: Brazilian Atlantic forest; Conservation genetics; Microsatellite; Population genetics; Tropical tree species

\section{INTRODUCTION}

Cariniana legalis (Mart.) O. Kuntze grows naturally throughout southeastern and northeastern Brazil, and is one of the most important historically harvested timber species. Its wood is light and is used in civil construction only for internal rooms, as well as in furniture manufacturing, because it is not very resistant to wood decay attacks. C. legalis is an endangered tropical tree species (FAO, 1996) that is pollinated by bees with wind-dispersed seeds (Carvalho, 2003). This species is endemic to the Atlantic Forest in Brazil and has a low population density $(<1$ tree/ha). Effective genetic conservation of a species requires knowledge of its mating system, genetic diversity, spatial genetic structure, and gene flow. Microsatellite markers or simple sequence repeats (SSRs) are suitable for such studies due to their very high polymorphism in terms of number of alleles (Ashley, 2010). However, for SSR markers to be used as genetic markers, it is necessary to know if their inheritance follows Mendelian rules (Brondani et al., 1998; Tarazi et al., 2010), as well as if loci are linked. Such information is particularly necessary for studies of genetic diversity, intra-population spatial genetic structure, mating systems, and gene flow because multilocus estimates are used and population genetic models are based on assumptions of Mendelian inheritance, absence of genetic linkage, and linkage equilibrium. Thus, studies related to Mendelian inheritance, absence of genetic linkage, and linkage equilibrium should be evaluated and reported when novel SSRs are developed. These were the aims of the present study. We investigated these genetic properties in seven microsatellite loci isolated from C. legalis by Tambarussi et al. (2013) and two heterologous microsatellite markers previously developed by Guidugli et al. (2010).

\section{MATERIAL AND METHODS}

\section{Sampling}

Open-pollinated seeds were collected from 15 seed-trees at the Floresta Estadual de Ibicatu ( $\left.22^{\circ} 46^{\prime} \mathrm{S}, 47^{\circ} 43^{\prime} \mathrm{W}, 540 \mathrm{~m}\right)$ and from seven seed-trees in Mogi-Guaçu (22 ${ }^{\circ} 16^{\prime} \mathrm{S}$, $47^{\circ} 11^{\prime}$ W, $568 \mathrm{~m}$ ), both located in São Paulo State, Brazil. In Ibicatu, 40 seeds were collected per seed-tree and in Mogi-Guaçu, 50 seeds from five seed-trees, and 100 seeds from two seedtrees were collected. All fruits were directly collected from the canopy of the trees to ensure that all seeds were siblings. Cambium tissue was also collected from the trunk of the seed-trees for DNA analysis. We also collected cambium tissue from another 40 adult trees in Ibicatu and a further 19 trees in Mogi-Guaçu.

\section{Microsatellite analysis}

From all adult trees, deoxyribonucleic acid (DNA) was extracted from $100 \mathrm{mg}$ adult 
stem bark material per tree using AnalytikJena DNA isolation kits. Seeds were germinated in vermiculite until the cotyledons emerged, and then DNA was extracted from 15- to 20-day-old seedlings using the method of Doyle and Doyle (1987).

Nine primers were used in this study. Seven of the primers were developed by Tambarussi et al. (2013) and two (Ce07 and Ce18) were developed by Guidugli et al. (2010). Microsatellite loci were amplified with polymerase chain reaction in a $15-\mu \mathrm{L}$ final volume using $\mathrm{GoTaq}^{\circledR}$ Colorless Master Mix containing $7.5 \mu \mathrm{L} 2 \mathrm{X}$ GoTaq ${ }^{\circledR}$ Colorless Master Mix, $10 \mu \mathrm{M}$ each primer, forward and reverse, $3.0 \mu \mathrm{L}$ nuclease-free water, and $7.5 \mathrm{ng}$ template DNA. The amplification program for all primers consisted of an initial denaturing step at $94^{\circ} \mathrm{C}$ for $1 \mathrm{~min}$; followed by 35 cycles each of amplification at $94^{\circ} \mathrm{C}$ for $1 \mathrm{~min}, 1 \mathrm{~min}$ at the specific annealing temperature of each primer pair (Tambarussi et al., 2013), and $72^{\circ} \mathrm{C}$ for $1 \mathrm{~min}$; and a final elongation step at $72^{\circ} \mathrm{C}$ for $10 \mathrm{~min}$. Amplifications were performed using a Mastercycler (Eppendorf, Hamburg, Germany). The amplification products $(2-\mu \mathrm{L}$ total reaction volume) were separated on a Fragment Analyzer ${ }^{\mathrm{TM}}$ Automated CE System (Advanced Analytical Technologies, Inc. [AATI], Ames, IA, USA) using the dsDNA Reagent Kit, 35-500 bp. Raw data were analyzed using the PROSize version 2.0 software (AATI).

\section{Analysis of inheritance}

We used the Gillet and Hattemer (1989) method to investigate the Mendelian inheritance of the C. legalis SSR loci. This method compares the genotype of a heterozygous maternal tree with the segregation of its open-pollinated progeny. This method assumes that the loci have regular segregation and its alleles follow classic Mendelian inheritance patterns, which is based on three main requirements: i) regular meiotic segregation during production of ovules; ii) random fertilization of ovules by each type of pollen; iii) no selection occurred between the moment of fertilization and genotyping of the seeds. The model also assumes that there is a co-dominant relationship among all alleles. The method further requires that the following conditions are met: 1) all progeny of a tree must possess a maternal allele, and 2) in cases of heterozygous parent trees (e.g., $A_{i} A_{j}, \mathrm{i} \neq \mathrm{j}$ ): a) among offspring, each individual must possess an allele of the maternal tree, $A_{i}$ or $A_{j}$; b) the number of heterozygous progeny $A_{i} A_{j}\left(n_{i j}\right)$ must equal the sum of homozygous progeny $A_{i} A_{i}\left(n_{i j}\right)$ and $A_{j} A_{j}\left(n_{j j}\right)$, or $n_{i j}=n_{i}+n_{j}$; and c) the number of heterozygous progeny $A_{i} A_{k}\left(n_{i k}\right)$ must equal the number of heterozygous progeny $A_{j} A_{k}\left(n_{j k}\right)$, or $n_{i k}=n_{j k}$, where $k \neq \mathrm{i}, \mathrm{j}$. The phenotypes observed in each heterozygous seed-tree were compared with the expected 1:1 segregation pattern by means of a maximum likelihood $G$-test (Sokal and Rohlf, 1981) based on the following formula (Equation 1):

$$
G=2\left[n_{i} \mathrm{~h}\left(\frac{n_{i}}{E(n)}\right)+n_{j} \mathrm{~h}\left(\frac{n_{j}}{E(n)}\right)\right]
$$

where $n_{i}$ and $n_{j}$ are the observed number of genotypes containing alleles $A_{i}$ and $A_{j}$, respectively, $\ln$ is the natural logarithm, and $E(n)$ is the expected number of genotypes for the alleles $A_{i}$ and $A_{j}$ based on Equation 2:

$$
E(n)=0.5\left(n_{i}+n_{j}\right) \quad \text { (Equation 2) }
$$


The $G$-test determines if the deviation between the observed and expected segregation is statistically significant or if deviations may be explained by chance. We also applied the Bonferroni correction for multiple comparisons $(95 \%, \alpha=0.05)$ to avoid false positives.

\section{Analysis of genetic linkage between pairwise loci}

To confirm the independence of allele segregation among different loci, we carried out a test of linkage between pairwise loci using genetic information from parent trees that were doubly heterozygous for two loci, and observed segregation in their progeny. In this case, the null hypothesis $\left(H_{\mathrm{O}}\right)$ is regular Mendelian segregation of 1:1:1:1. The hypothesis of regular segregation between pairwise loci was accepted or discarded based on a maximum likelihood $G$-test (Sokal and Rohlf, 1981), shown in Equation 3, performed for each progeny. For each cell the expected frequency under the null hypothesis of segregation 1:1:1:1 was calculated as:

$$
G=2\left[n_{i k} \ln \left(\frac{n_{i k}}{E(n)}\right)+n_{i l} \ln \left(\frac{n_{i l}}{E(n)}\right)+n_{j k} \ln \left(\frac{n_{j k}}{E(n)}\right)+n_{j l} \ln \left(\frac{n_{j l}}{E(n)}\right)\right] \quad \text { (Equation 3) }
$$

where, $n_{i k}, n_{i l}, n_{j k}$, and $n_{j l}$ are the observed number of phenotypes $A_{i} B_{k}, A_{i} B_{l}, A_{j} B_{k}$, and $A_{j} B_{l}$, respectively, $E(n)$ is the expected number of genotypes $A_{i} B_{k}, A_{i} B_{l}, A_{j} B_{k}$, and $A_{j} B_{l}$, respectively, ln is the natural logarithm, and $E(n)$ is calculated as in Equation 4:

$$
E(n)=0.25\left(n_{i k}+n_{i l}+n_{j k}+n_{j l}\right)
$$

We again applied the Bonferroni correction for multiple comparisons $(95 \%, \alpha=0.05)$ to avoid false positives.

\section{Analysis of linkage disequilibrium}

The genotypic disequilibrium test was performed only for adult trees, since genotypic disequilibrium is obviously expected in progeny arrays because all descendants always receive a maternal allele, which generates an "apparent genotypic imbalance". The genotypic disequilibrium test was carried out using the FSTAT program (Goudet, 1995). The $H_{\mathrm{O}}$ was tested and the probability of the test was used to determine the imbalance between all pairwise loci. For the avoidance of false positives, we used a Bonferroni correction at $95 \%$ probability $(\alpha=0.05)$.

\section{RESULTS}

The results showed a significant deviation from the expected 1:1 Mendelian segregation pattern in only 22 cases of 589 tests (3.7\%) (Table 1$)$. For the Ce07, Cle12, and Cle04 loci, no deviation was observed. In the other loci, some deviations were detected in different progenies. 


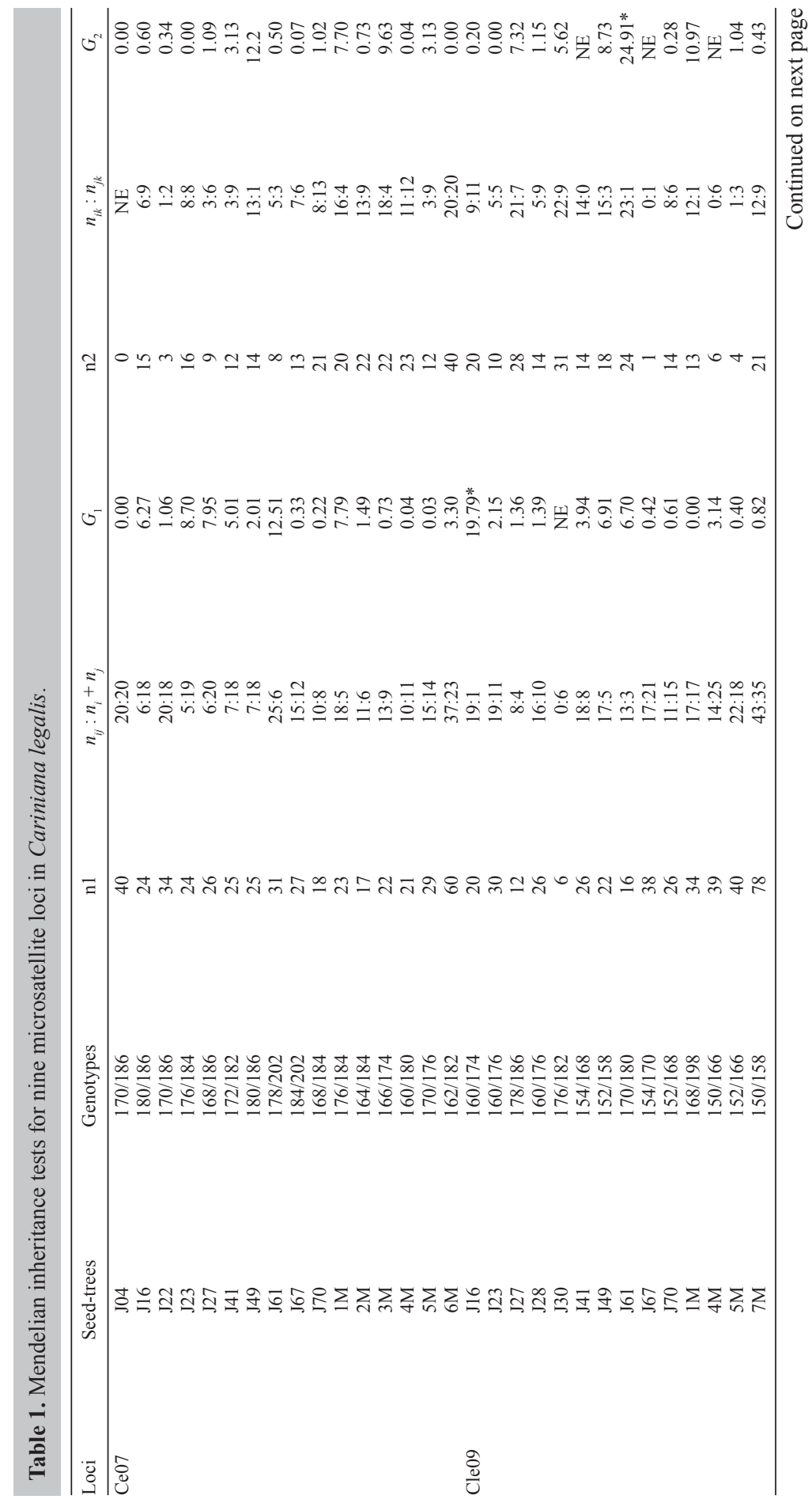




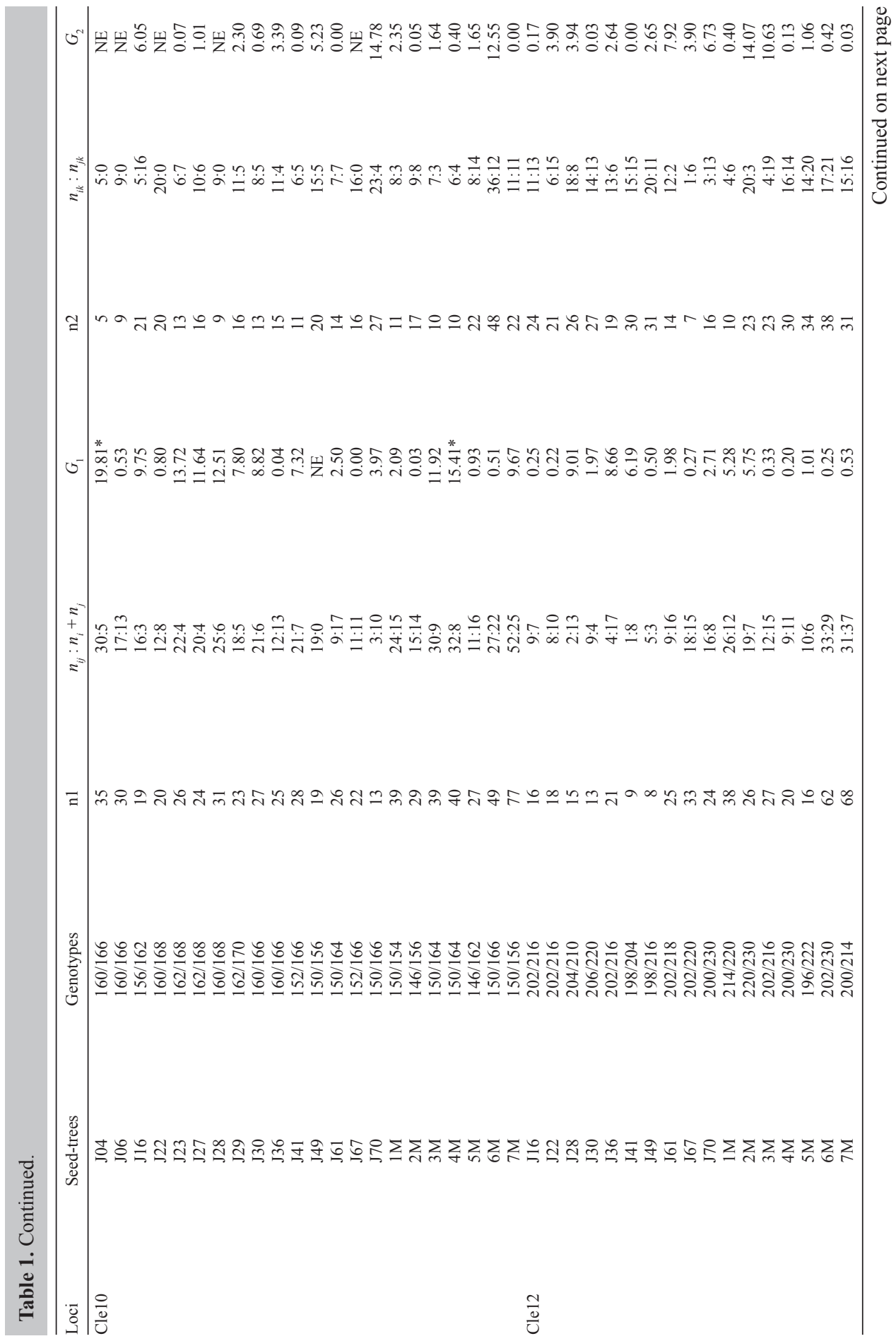




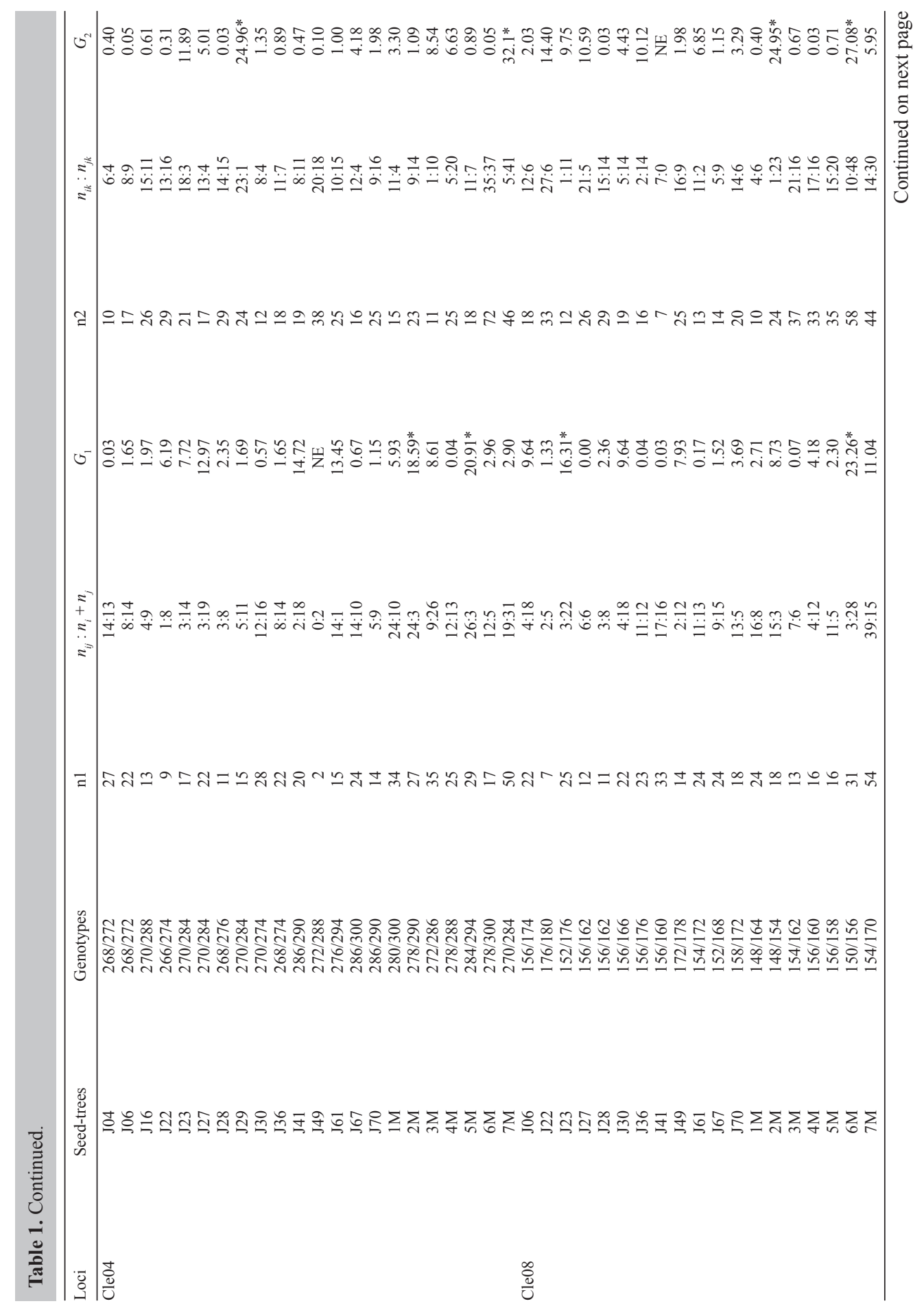




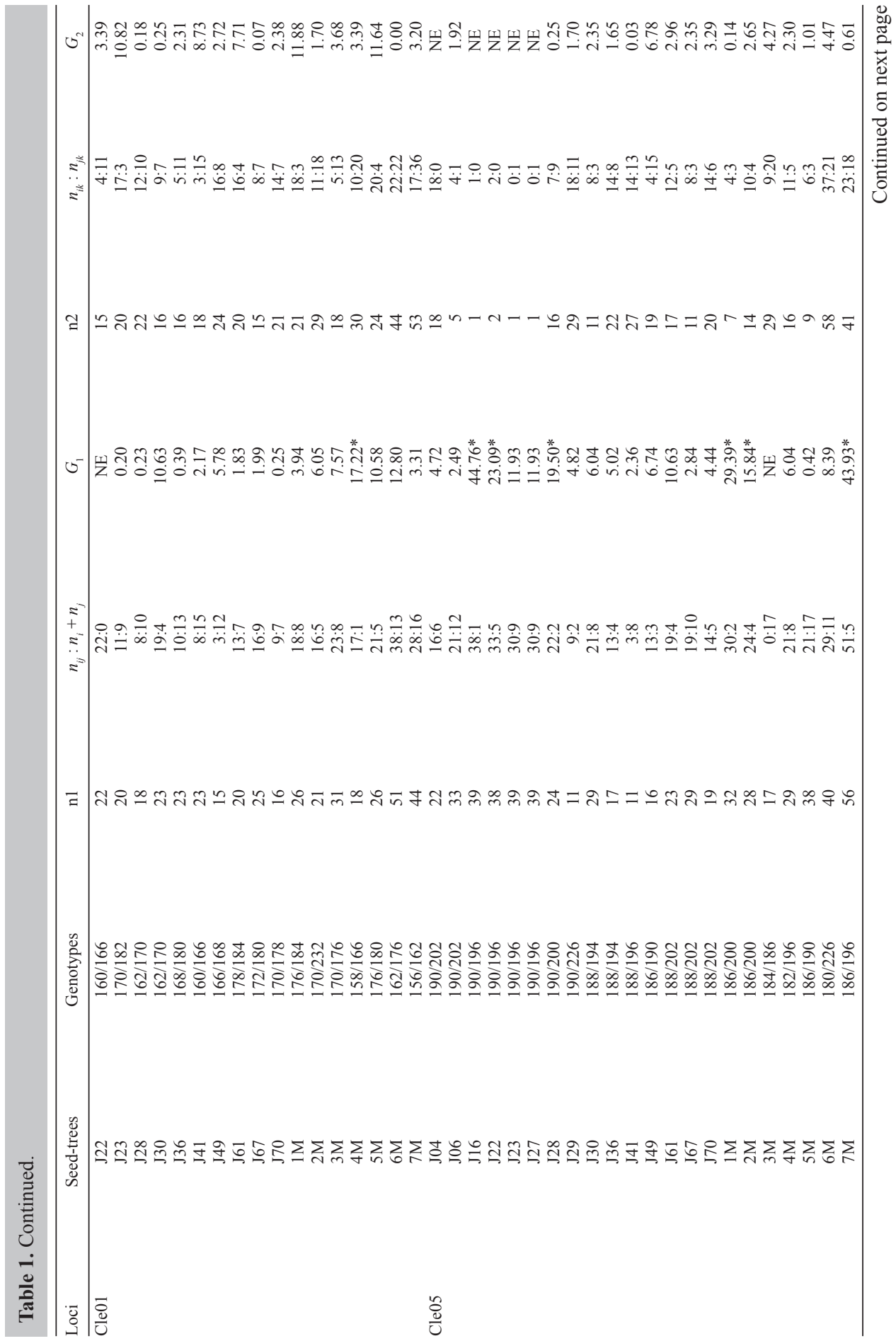




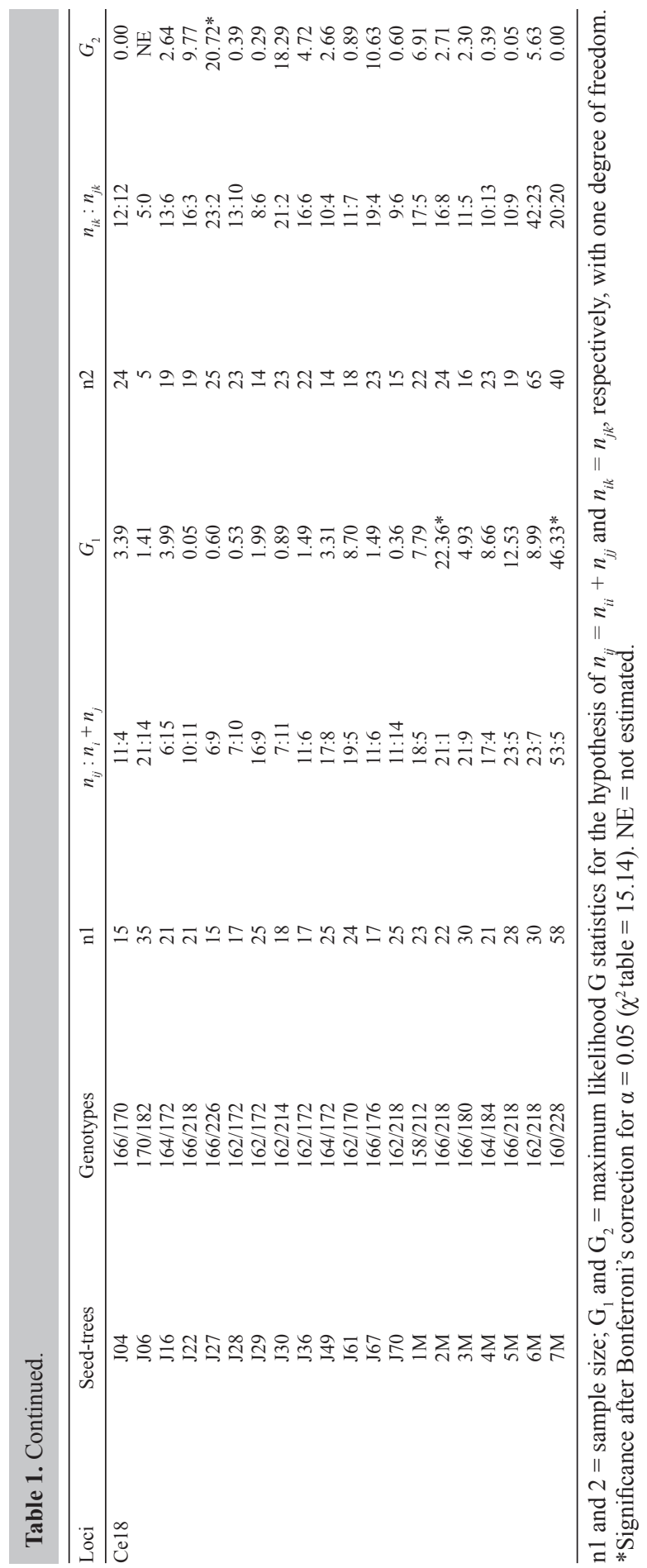


The $G$-test was used to compare the observed values with those expected under the null hypothesis for the 1:1:1:1 segregation of genotypes between two heterozygous SSR loci. After the Bonferroni correction, only $2.8 \%$ of the 594 linkage tests performed (Table 2) were significant. However, in all cases in which significant linkage was observed, it occurred in different pairs of loci of different sampled progenies. Moreover, in the largest group of sampled progenies $(\mathrm{N}=100)$, all pairwise loci adjusted to the expected 1:1:1:1 Mendelian segregation. On the other hand, the majority of progeny adhered to the expected 1:1:1:1 Mendelian inheritance for the same pairs of loci analyzed.

Genotypic disequilibrium in molecular markers is one of the basic assumptions for use in genetic diversity and structure, mating system, and paternity analyses. After Bonferroni correction, the results showed no significant evidence of genotypic disequilibrium between pairwise loci. Only $9.7 \%$ of pairwise loci showed linkage (Table 3 ). This was most likely a consequence of the small sample size within families. Combining this result with that observed in the test of linkage between loci, it appears that this imbalance was not associated with physical linkage between the loci.

\section{DISCUSSION}

These few cases of deviation of Mendelian segregation can be influenced by sexlinkage, physical association with genes under strong selection, centers of recombination, transposable elements, or processes during meiosis such as non-disjunction or meiotic drive (Selkoe and Toonen, 2006). Some observed deviations were also likely caused by the reduced number of seedlings per progeny (ranging from 40 to100).

Again, it is happened in null hypothesis for the 1:1:1:1 segregation. With the reduced number of seedlings per progenies, deviations were expected by chance. This was apparent by the smaller deviations obtained for Mogi-Guaçu ( $\mathrm{N}=50$ to 100 per seed-tree) when compared with the Ibicatu result $(\mathrm{N}=40)$ samples. This suggests that the deviations found in groups of smaller sample size were sampling artifacts. Tarazi et al. (2010), using 20 seeds per progeny collected from 28 seed-trees, found two loci with $20 \%$ significant genetic linkage in Copaifera langsdorffii. Carneiro et al. (2012) observed similar results in Hymenaea courbaril with sample sizes ranging from 13 to 20 seeds per seed-tree. Both authors suggested that the small number of progenies were the likely cause of these observed deviations.

These results are expected in studies involving species with relatively large numbers of chromosomes and a small number of markers. In such situations, the probability of finding markers localized in a given chromosome is small. In general, Cariniana species have $\mathrm{X}=17$ chromosomes, and nine microsatellite markers were used in the present study. It is also important to mention that the majority of investigations involving wild species have been carried out using six locus markers. In only $10 \%$ of such studies were more than 10 loci used (Koskinen et al., 2004). Therefore, our study was based on more loci than are commonly used.

Also, genotypic disequilibrium can be generated by self-pollination, correlated mating, mating among relatives, genetic bottleneck effects, founder effects, and natural and artificial selection. The bottleneck effect is a possible explanation for the observed deviations in the Ibicatu population, which recently underwent strong forest fragmentation. Belaj et al. (2007) observed that among a total of 308 tests for linkage disequilibrium between pairs of loci, $6 \%$ were significant. It is known that population structure increases linkage disequilibrium in the 


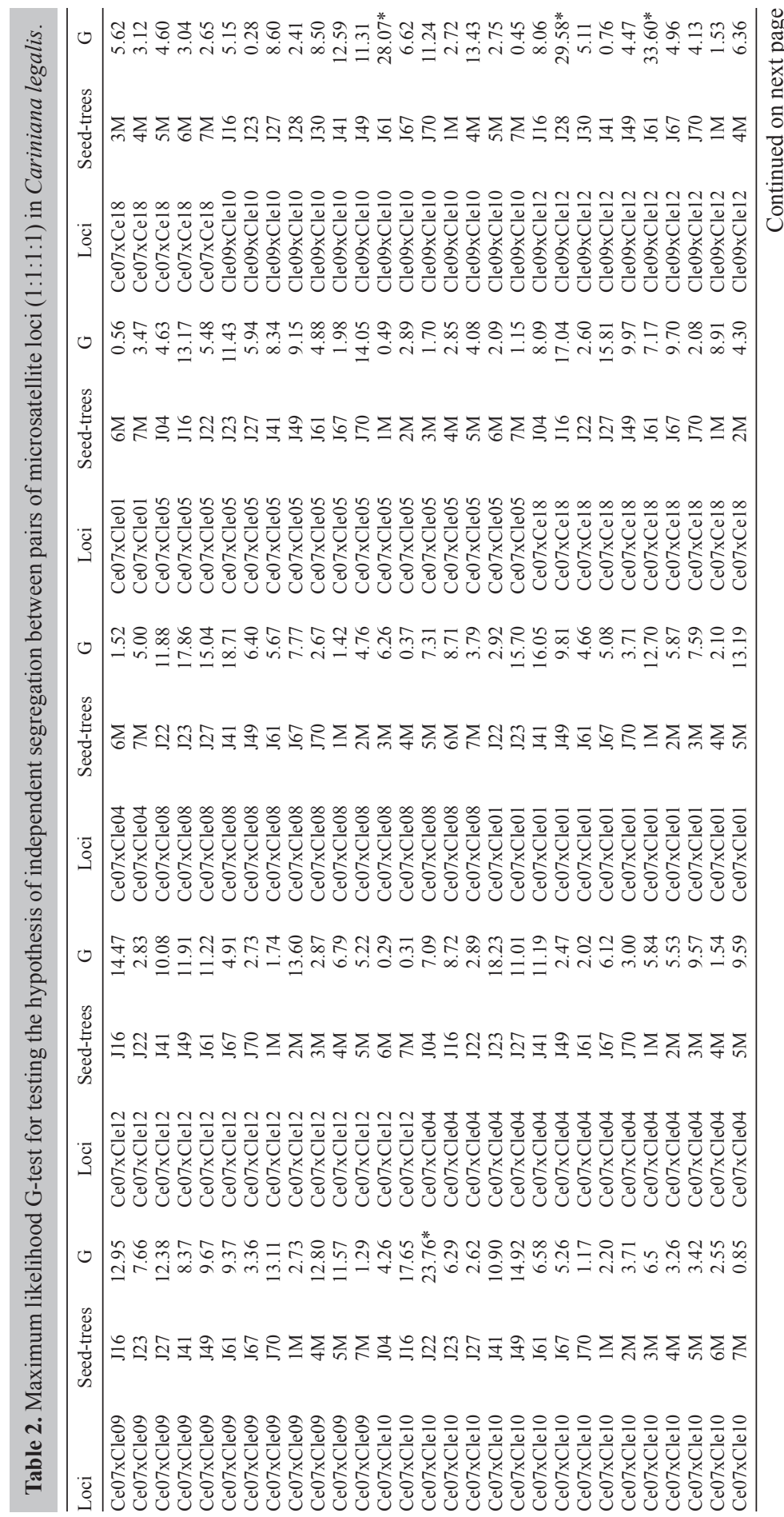




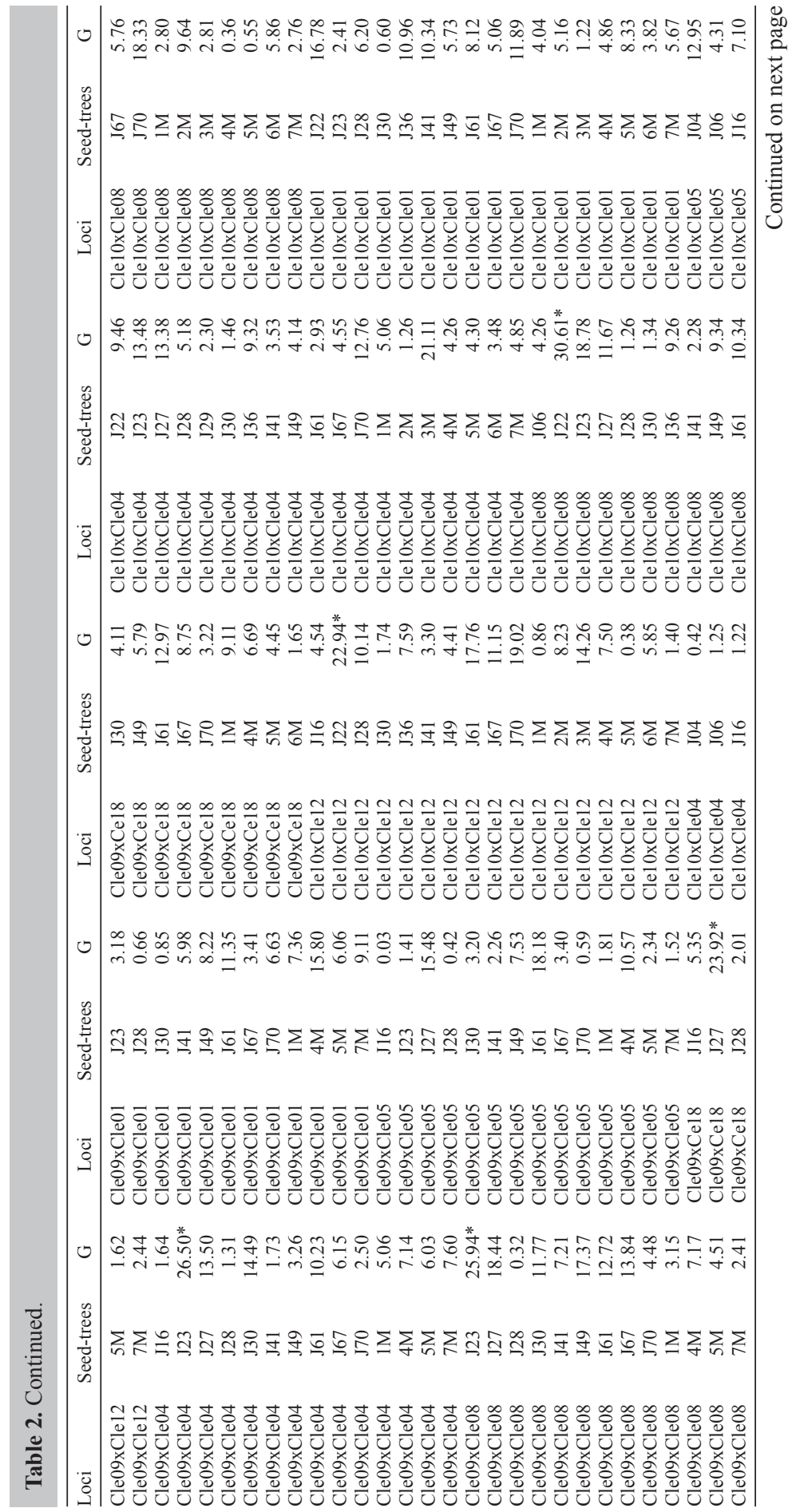




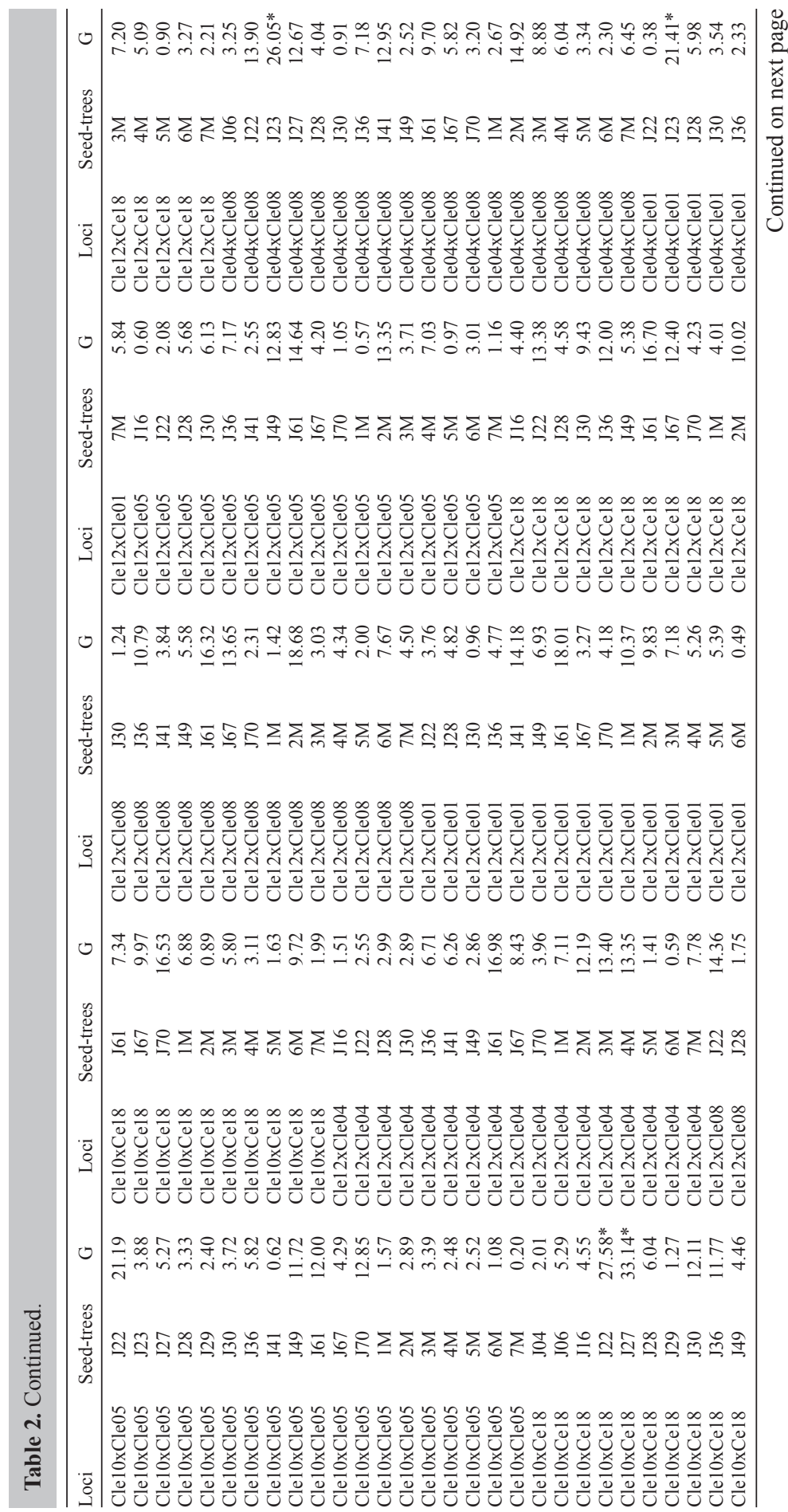




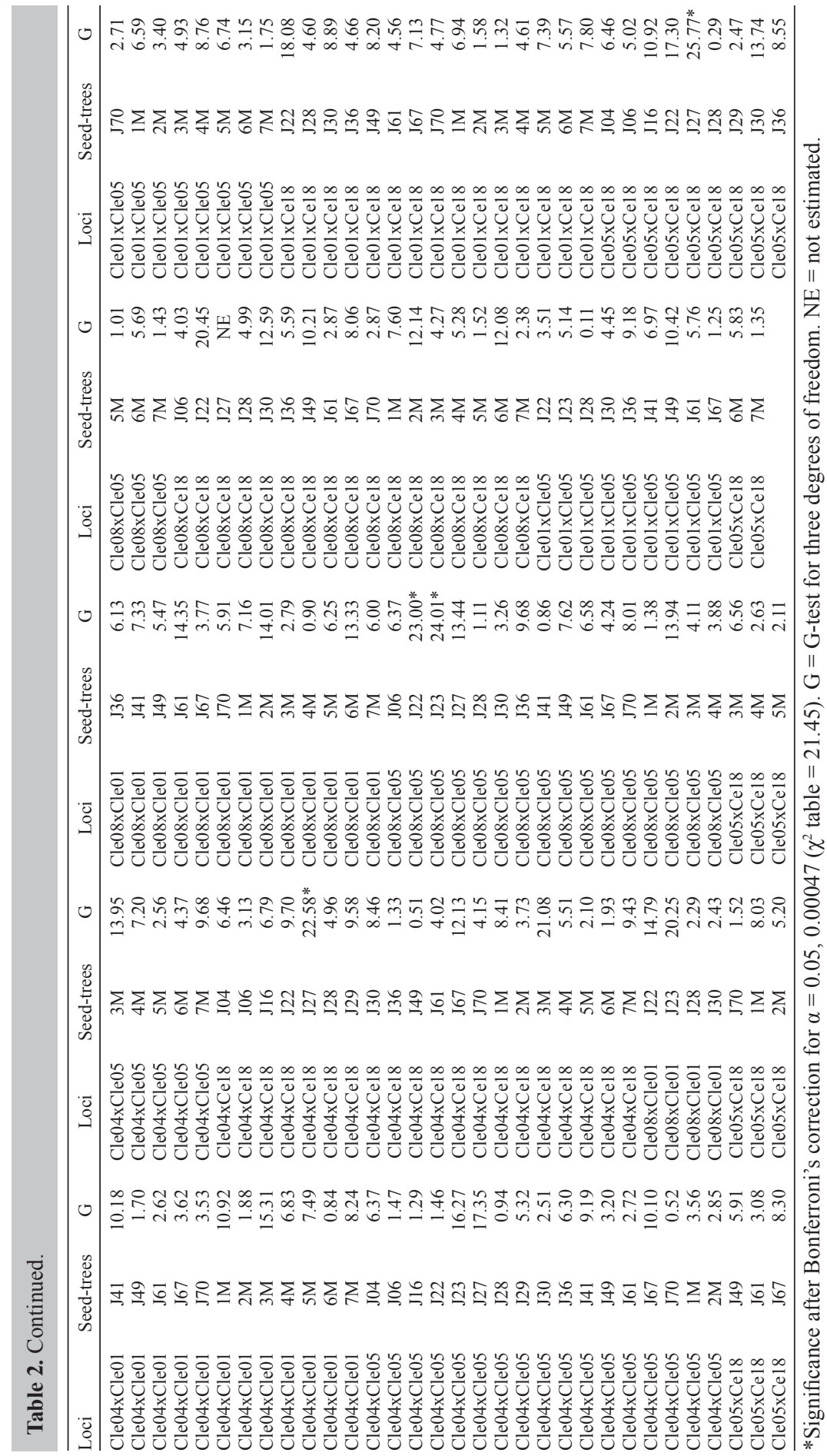


Table 3. Genotypic disequilibrium between pairwise microsatellite loci in adult trees of Cariniana legalis.

\begin{tabular}{|c|c|c|}
\hline \multirow[t]{2}{*}{ Pairwise loci } & \multicolumn{2}{|c|}{ Locations } \\
\hline & Ibicatu & Mogi-Guaçu \\
\hline Ce07xCle09 & 0.14861 & 0.39444 \\
\hline $\mathrm{Ce} 07 \mathrm{xCle} 10$ & 0.07847 & 1.0 \\
\hline $\mathrm{Ce} 07 \mathrm{xCle} 12$ & 0.44792 & 1.0 \\
\hline $\mathrm{Ce} 07 \mathrm{xCle} 04$ & 0.35139 & 1.0 \\
\hline $\mathrm{Ce} 07 \mathrm{xCle} 08$ & 0.44236 & 1.0 \\
\hline $\mathrm{Ce} 07 \mathrm{xCle} 01$ & 0.05972 & 0.20625 \\
\hline $\mathrm{Ce} 07 \mathrm{xCle} 05$ & 0.02014 & 1.0 \\
\hline $\mathrm{Ce} 07 \mathrm{xCe} 18$ & 0.03056 & 0.06736 \\
\hline Cle09xCle10 & $0.00069 *$ & 0.01875 \\
\hline Cle09xCle12 & $0.00069^{*}$ & 0.24931 \\
\hline Cle $09 x$ Cle 04 & 0.07361 & 1.0 \\
\hline Cle $09 x$ xle08 & 0.09722 & 1.0 \\
\hline Cle $09 x$ Cle 01 & 0.00694 & 0.10208 \\
\hline Cle09xCle05 & $0.00069 *$ & 0.19444 \\
\hline $\mathrm{Cle} 09 \mathrm{xCe} 18$ & 0.07153 & 0.21181 \\
\hline Cle10xCle12 & 0.06319 & 0.61667 \\
\hline Cle10xCle04 & $0.00069 *$ & 0.12083 \\
\hline Cle10xCle08 & 0.20972 & 1.0 \\
\hline Cle10xCle01 & 0.01736 & 1.0 \\
\hline Cle10xCle05 & $0.00069 *$ & 1.0 \\
\hline Cle10xCe18 & 0.00417 & 0.02986 \\
\hline Cle $12 x C l e 04$ & 0.03542 & 1.0 \\
\hline Cle12xCle08 & 0.07917 & 0.28194 \\
\hline Cle12xCle01 & 0.47222 & 0.45972 \\
\hline Cle12xCle05 & $0.00069 *$ & 0.00208 \\
\hline Cle12xCe18 & 0.46458 & 0.33472 \\
\hline Cle $04 x$ Cle 08 & 0.16458 & 1.0 \\
\hline Cle $04 x$ Cle 01 & 0.09931 & 1.0 \\
\hline Cle $04 x$ Cle05 & 0.01458 & 1.0 \\
\hline Cle04xCe18 & 0.68611 & 0.39444 \\
\hline Cle $08 x$ Cle 01 & 0.33889 & 0.16944 \\
\hline Cle $08 x$ Cle 05 & 0.16389 & 0.24861 \\
\hline Cle $08 x$ Ce18 & 0.80417 & 0.24861 \\
\hline Cle $01 x C l e 05$ & $0.00069 *$ & 1.0 \\
\hline Cle $01 x C e 18$ & 0.79722 & 0.29444 \\
\hline Cle $05 x \mathrm{xe} 18$ & 0.32014 & 0.78403 \\
\hline
\end{tabular}

The values represent the probability of genotypic disequilibrium after 1000 permutations of alleles among individuals. Probability after Bonferroni's corrections: $\mathrm{P}=0.00069(\alpha=0.05)$.

genome. Guidugli et al. (2009) found significant genotypic disequilibrium in only one pair of SSR loci for C. estrellensis. However, Tarazi et al. (2010) observed genotypic disequilibrium between all 28 combinations in pairs of SSR loci in C. langsdorffii.

The seven microsatellite loci and the two heterologous microsatellite markers developed for C. legalis presented a Mendelian inheritance pattern, no genetic linkage, and negligible genotypic disequilibrium. Therefore, this analysis indicated that this set of SSR loci could be used without restriction in studies on the genetic diversity and structure, mating system, and parentage analysis of $C$. legalis.

\section{ACKNOWLEDGMENTS}

Research supported by Fundação de Amparo à Pesquisa do Estado de São Paulo (FAPESP) (\#2010/10704-7) and by Conselho Nacional de Desenvolvimento Científico e Tecnológico (CNPq; Project \#470491/2010-8). The authors would like to thank FAPESP for 
financial support provided to E.V. Tambarussi (Project \#2010/12354-3) and CNPq for financial support to A.M. Sebbenn, M.L.M. Freitas, and R. Vencovsky. Special thanks to Maria Andréia Moreno and Elza Ferraz for their laboratory help, and to Wladimir Correa and Dirceu de Souza for their help in collecting plant samples. Finally, we thank two reviewers whose suggestions and corrections improved a previous version of this manuscript.

\section{REFERENCES}

Ashley MV (2010). Plant parentage, pollination, and dispersal: How DNA microsatellites have altered the landscape. Crit. Rev. Plant Sci. 29: 148-161.

Belaj A, Muñoz-Diez C, Baldoni L, Porceddu A, et al. (2007). Genetic diversity and population structure of wild olives from the North-western Mediterranean assessed by SSR markers. Ann. Bot. 100: 449-458.

Brondani RPV, Brondani C, Tarchini R and Grattapaglia D (1998). Development, characterization and mapping of microsatellite markers in Eucalyptus grandis and E. urophylla. Theor. Appl. Genet. 97: 816-827.

Carneiro FS, Lacerda AE, Lemes MR, Gribel R, et al. (2012). Mendelian inheritance, linkage and genotypic disequilibrium in microsatellite loci isolated from Hymenaea courbaril (Leguminosae). Genet. Mol. Res. 11: 1942-1948.

Carvalho PER (2003). Espécies Florestais Brasileiras: Recomendações Silviculturais, Potencialidades e Uso da Madeira. EMBRAPA - CNPF, Colombo.

Doyle JJ and Doyle JL (1987). A rapid DNA isolation procedure for small quantities of fresh leaf tissue. Phytochemistry 19: 11-15.

FAO (1996). Panel of Experts on Forest Gene Resources. Ninth Session. Food and Agriculture Organization of the United Nation, Roma.

Gillet E and Hattemer HH (1989). Genetic analysis of isoenzyme phenotypes using single tree progenies. Heredity 63: 135-141.

Goudet J (1995). FSTAT (Version 2.9.3.2.): a computer program to calculate F-statistics. J. Hered. 86: 485-486.

Guidugli MC, Campos T, Sousa ACB, Feres JM, et al. (2009). Development and characterization of 15 microsatellite loci for Cariniana estrellensis and transferability to Cariniana legalis, two endangered tropical tree species. Conserv. Genet. 10: 1001-1004.

Guidugli MC, Accoroni KAG, Mestriner MA, Contel EPB, et al. (2010). Genetic characterization of 12 heterologous microsatellite markers for the giant tropical tree Cariniana legalis (Lecythidaceae). Genet. Mol. Biol. 33: 131-134.

Koskinen MT, Hirvonen H, Landry PA and Primmer CR (2004). The benefits of increasing the number of microsatellites utilized in genetic population studies: an empirical perspective. Hereditas 141: 61-67.

Selkoe1 KA and Toonen RJ (2006). Microsatellites for ecologists: a practical guide to using and evaluating microsatellite markers. Ecol. Lett. 9: 615-629.

Sokal RR and Rohlf FJ (1981). Biometry: The Principles and Practice of Statistics in Biological Research. Copyright Ltd., New York.

Tambarussi EV, Sebbenn AM, Moreno MA, Ferraz EM, et al. (2013). Microsatellite markers for Cariniana legalis (Lecythidaceae) and their transferability to C. estrellensis. Appl. Plant Sci. 1: 1200493.

Tarazi R, Sebbenn AM, Mollinari M and Vencovsky R (2010). Mendelian inheritance, linkage and linkage disequilibrium in microsatellite loci of Copaifera langsdorffii Desf. Conserv. Genet. Resour. 2: 201-204. 